\title{
SUSTENTABILIDADE DE PRODUTORES RURAIS EM CAICÓ, RIO GRANDE DO NORTE
}

\author{
Huanna Raíssa Alves de Lucena ${ }^{1}$, Anderson Bruno Anacleto de Andrade 2 , Patrício Borges Maracajá \\ Hugerles Sales Silva ${ }^{4}$, José Lucas Guilherme Santos ${ }^{5}$, Thiago Alves Pimenta ${ }^{6}$
}

\begin{abstract}
RESUMO - Objetivou-se avaliar o nível de sustentabilidade entre produtores que residem na zona rural e urbana do município de Caicó no estado do Rio Grande do Norte, identificando as características da população, assim como indicadores relacionados à qualidade de vida, capital social e preservação ambiental. Para isso, realizou-se aplicação de questionários com 40 produtores, com 50\% da amostra residindo na sede do município e o restante em comunidades rurais. O município de Caicó apresenta-se com uma maior parcela de produtores do gênero masculino com idades que variaram de 23 a 84 anos. Entre as atividades agropecuárias desenvolvidas pelos produtores as mais bem avaliadas em relação ao fator econômico foram à bovinocultura e a ovinocultura, para os dois grupos. Para Índice de Qualidade de Vida da zona rural observou-se desempenho médio, porém, na zona urbana esse índice se enquadrou como elevado, com valor de 0,992. O Índice de Capital Social também diferenciou entre as populações pesquisadas, para os produtores moradores da cidade o índice foi baixo, com valor de 0,075 , para os residentes rurais a classificação foi média $(0,650)$. Em relação preservação ambiental dos produtores, essa foi definida como baixa nas duas realidades estudadas, em decorrência principalmente da utilização de fogo nas atividades agropecuárias. Nesse contexto, verificou-se que tanto os produtores da zona rural quanto os que residem da zona urbana apresentam nível médio de sustentabilidade.
\end{abstract}

Palavras chave: comportamento ambiental, desenvolvimento sustentável, produção rural.

\section{SUSTAINABILITY OF FARMERS IN THE RURAL AREA OF CAICÓ, RIO GRANDE DO NORTE, BRAZIL}

\begin{abstract}
The objective of this study was to evaluate the level of sustainability among farmers residing in the rural and urban areas of Caicó, State of Rio Grande do Norte, Brazil. We identify the characteristics of the population, as well as indicators related to life quality, social capital, and environmental preservation. Therefore, we applied questionnaires with 40 farmers, in which $50 \%$ live in the rural area and $50 \%$ at the city. Male producers, aged between 23 and 84, make up the majority of workers at the municipality of Caicó. Among the activities developed by the producers, livestock and sheep farming were the best evaluated about the economic factor, for the two groups sampled. An average life quality index was observed for farmers living in rural area, but a high index was found for the farmers that live in the urban area (0.992). However, producers living in the urban zone showed a low Social Capital Index (0.075) while the index was higher (0.650) for rural residents. Both rural producers had low preservation practices, due to the use of fire in agricultural activities, leading to a small value of preservation index. In this context, we verified an average level of sustainability for both kinds of farmers.
\end{abstract}

Keywords: environmental behavior, rural production, sustainable development.

\footnotetext{
${ }^{1}$ Engenheira Ambiental pela Universidade Federal de Campina Grande. E-mail: huannaraissa@gmail.com.

${ }^{2}$ Doutorando em Proteção de Plantas pela Universidade Federal de Alagoas. E-mail: bdeandrade3@gmail.com.

${ }^{3}$ Professor da Universidade Federal de Campina Grande. E-mail: patricomaracaja@gmail.com.

${ }^{4}$ Doutor em Engenharia elétrica pela Universidade Federal de Campina Grande. E-mail: hugerles.silva@ee.ufcg.edu.br.

${ }^{5}$ Mestre em Sistemas Agroindustriais pela Universidade Federal de Campina Grande. E-mail: lucas1guilherme@hotmail.com.

${ }^{6}$ Doutorando em Proteção de Plantas pela Universidade Federal de Alagoas. E-mail: tpimenta62@gmail.com.
} 


\section{INTRODUÇ̃̃O}

O desenvolvimento sustentável reveste-se na expectativa da adequação ambiental, social e econômica para a sociedade, de maneira que as futuras gerações possam desfrutar das mesmas oportunidades e benefícios (Loureiro et al., 2016). Na procura de formas sustentáveis para atender as necessidades contínuas da população é necessário verificar os modelos produtivos, principalmente, os que estão envolvidos na produção de alimentos. Com isso os sistemas de indicadores surgem nesse cenário como uma alternativa para compreensão e minimização das atividades nocivas contra o meio ambiente (Sales \& Cândido, 2014).

Os indicadores de sustentabilidade são uma ferramenta que auxilia na gestão de políticas públicas, contribuindo para o planejamento, monitoramento e processo decisório, em busca do desenvolvimento sustentável local (Barros \& Silveira, 2019).

Os indicadores são usados como ferramentas de avaliação de sustentabilidade no meio rural, podendo ser um apoio importante na tomada de decisão de produtores rurais, para implantação de formas de produção sustentáveis, contribuindo para o desenvolvimento de propriedades rurais (Seidler et al., 2018).

O conceito de sustentabilidade em negócios rurais contempla questões relacionadas aos aspectos econômicos, sociais e ambientais, sendo que, ao fator econômico ligase à produção, distribuição e consumo de bens e serviços; o social trata-se do capital humano do empreendimento, sociedade como um todo e das relações entre os membros da comunidade; e o fator ambiental refere-se ao capital natural que deve ser preservado no pequeno, médio e longo prazo (Elkington, 1997).

Nesse sentido, a investigação das condições sustentáveis dos produtores rurais é uma ferramenta para evidenciar a realidade produtiva da comunidade, contribuindo com a elucidação de quais variáveis envolvidas necessitam de atenção para promover as atividades de forma sustentáveis. Com isso, objetivou-se avaliar o nível de sustentabilidade dos produtores rurais que residem na zona rural e urbana do município de Caicó no estado do Rio Grande do Norte por meio de indicadores de sustentabilidade baseado em aspectos econômicos, sociais e ambientais.

\section{MATERIAL E MÉTODOS}

O trabalho foi realizado no município de Caicó situado na microrregião Seridó Ocidental, abrangendo uma área de $1215 \mathrm{~km}^{2}$, a sede do município tem uma altitude média de $151 \mathrm{~m}$ e coordenadas $06^{\circ} 27^{\prime} 28,8^{\prime \prime}$ de latitude sul e $37^{\circ} 05^{\prime} 52,8^{\prime \prime}$ de longitude oeste (Figura 1 ).

De acordo com o último censo do Instituto Brasileiro de Geografia e Estatística (2010), possui uma população de 62709 habitantes e 5248 residentes da zona rural. O município possui 18616 domicílios permanentes, sendo 17141 na zona urbana e 1475 na zona rural com densidade demográfica de $51,04 \mathrm{hab} / \mathrm{km}^{2}$, com Índice de Desenvolvimento Humano Municipal (IDHM) de 0,710 que mede o grau da renda, da longevidade e da educação, assim estando situado na faixa de alto desenvolvimento humano (IDHM entre 0,7 e 0,799) (IBGE, 2010).

O trabalho caracteriza-se como uma pesquisa aplicada, de característica exploratória de acordo com os objetivos, com procedimento de levantamento a partir de duas amostras, os produtores residentes na zona rural e urbana do município de Caicó.

Os dados foram obtidos mediante aplicação de questionários, diretamente aos produtores rurais do município, sendo entrevistados quarenta produtores, vinte que residem na zona urbana e vinte na zona rural.

Os questionários específicos foram adaptados a partir do método utilizado por Khan \& Silva (2002) com a finalidade de se obter um maior número de informações possíveis acerca dos indicadores que definem o nível de sustentabilidade dos produtores do município.

O Índice de Sustentabilidade foi calculado considerando variáveis que representam o desenvolvimento econômico, social e ambiental, utilizando-se os Índices de Qualidade de Vida (IQV), Capital Social (ICS) e Ambiental (IA). Esses índices foram definidos conforme Khan \& Silva (2002), utilizando-se a equação 1 e a contribuição de cada indicador foram obtidos de acordo com a equação 2 .

$$
\begin{aligned}
& \mathrm{Ic}=\frac{1}{\mathrm{n}} \sum_{\mathrm{j}=1}^{\mathrm{n}}\left(\sum_{\mathrm{i}=1}^{\mathrm{m}} \mathrm{E}_{\mathrm{ij}} \mathrm{P}_{\mathrm{ij}}\right) \cdot\left(\sum_{\mathrm{i}=1}^{\mathrm{m}} \mathrm{E} \max _{\mathrm{i}} \mathrm{P} \max _{\mathrm{i}}\right)^{-1} \\
& C_{i}=\left(\sum_{i=1}^{n} E_{i j} \cdot P_{i j}\right) \cdot\left[n\left(\sum_{i=1}^{m} E \max _{i} P \max _{i}\right)\right]^{-1}
\end{aligned}
$$

Em que: Ic: são os índices calculados; Eij: Escore do i-ésimo indicador, alcançado pelo j-ésimo produtor; Pij: Peso do i-ésimo indicador, alcançado pelo j-ésimo produtor; $\mathrm{i}: 1, \ldots, \mathrm{m}$ (indicadores); $\mathrm{j}: 1, \ldots, \mathrm{n}$ (produtores); Pmaxi: Peso máximo do i-ésimo indicador; Emaxi: Escore máximo do i-ésimo indicador; Ci: Contribuição do indicador (i) no índice dos produtores. 


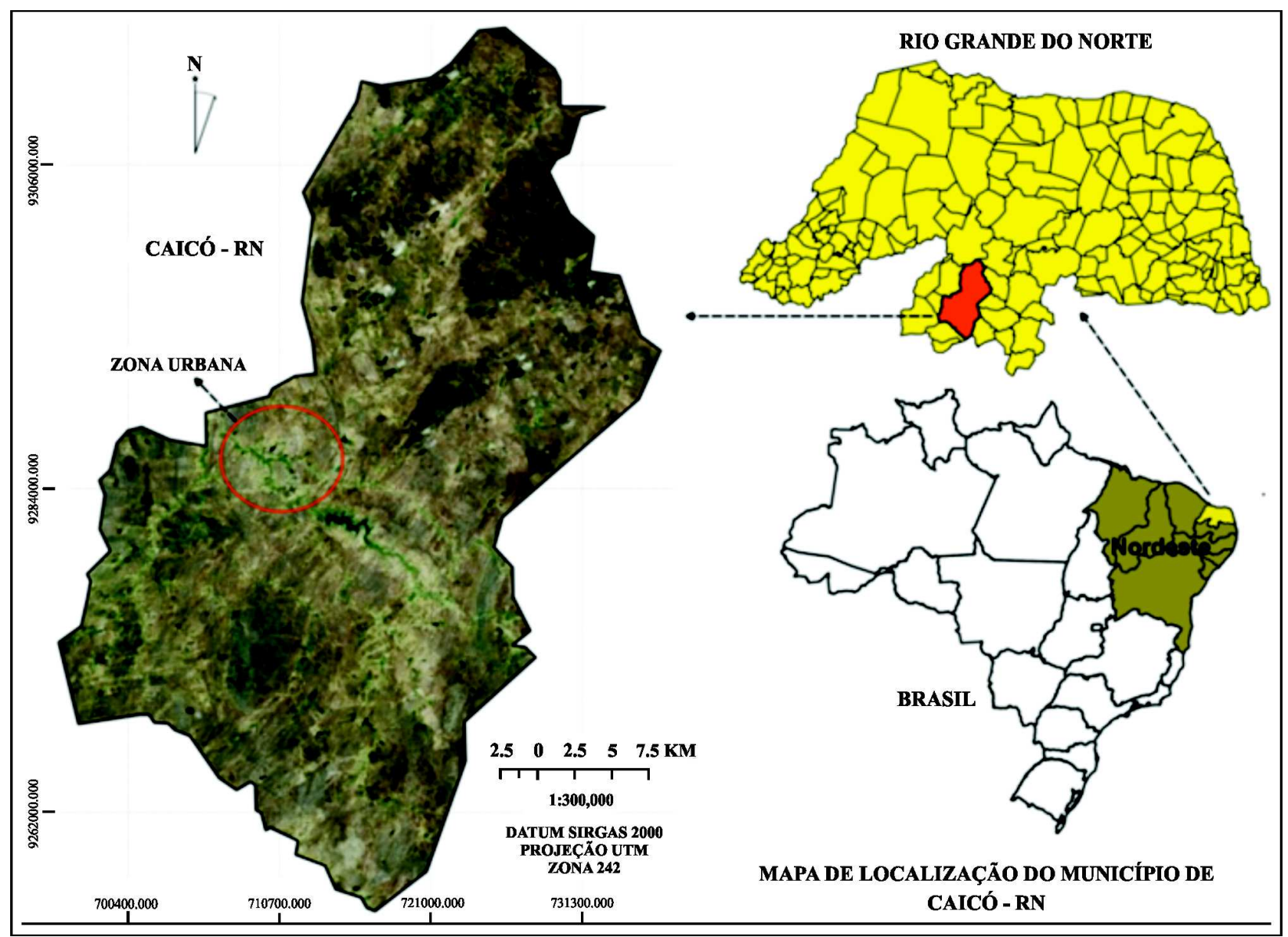

Figura 1 - Localização do município de Caicó no estado do Rio Grande do Norte, Brasil.

Fonte: Autor principal (2017).

Para o Índice de Qualidade de Vida (IQV) usou-se a percepção do indivíduo a sua posição de vida no contexto de valores e sistema em relação aos seus objetivos, expectativas, padrões e preocupações baseandose no estabelecimento de indicadores de educação, saúde, habitação, aspectos sanitários, lazer e posse de bens duráveis (Fernandes et al., 1997).

A comparação entre os valores indicativos dos componentes do IQV para os produtores foi realizada me- diante avaliação dos indicadores com escores que variam entre 0 e 3 , conforme observa-se na Tabela 1.

O Índice de Capital Social (ICS) foi estabelecido com intuito de mensurar a participação e o nível de envolvimento dos produtores em associações, cooperativas, sindicatos e demais grupos de organização rural em atividades políticas e culturais. Considerou-se a participação dos atribuindo-lhes valores 0 (zero) para não participação e 1 (um) para participação (Tabela 2). 
Tabela 1 - Escores para os indicadores avaliados na composição do Índice de Qualidade de Vida

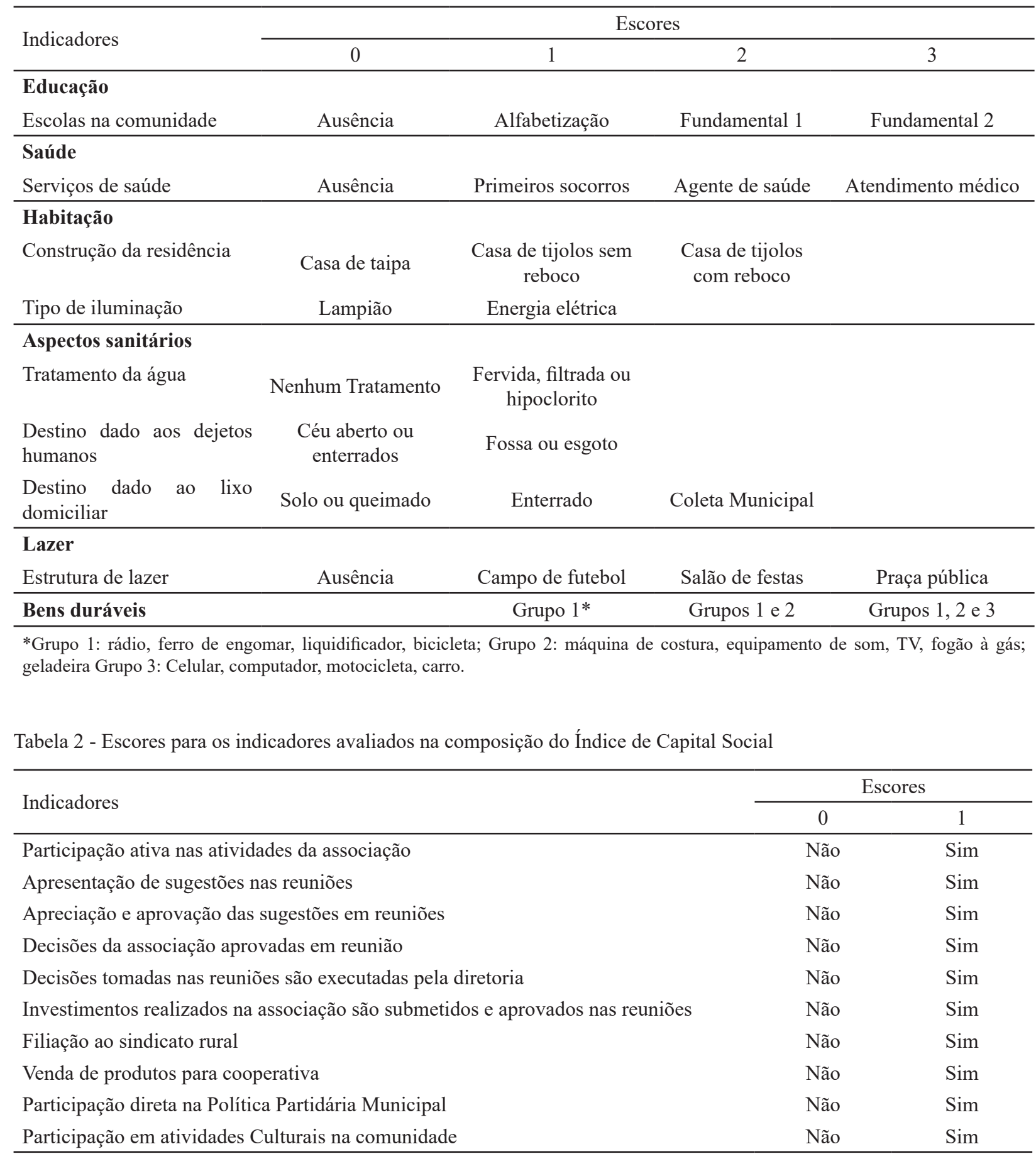


O Índice Ambiental (IA) foi estabelecido seguindo a metodologia proposta por Khan \& Silva (2002), com indicadores tendo como base atividades desenvolvidas pelos produtores que promovam práticas conservacionistas e representativas para a preservação ambiental, atribuído valores de 0 a 2 (Tabela 3 ).

Tabela 3 - Escores para os indicadores avaliados na composição do Índice Ambiental

\begin{tabular}{lccc}
\hline \multirow{2}{*}{ Indicadores } & \multicolumn{3}{c}{ Escores } \\
\cline { 2 - 4 } & 0 & 1 & 2 \\
\hline Conservação do solo & Nenhum método & Práticas mecânicas & Práticas Biológicas \\
Controle fitossanitário & Agrotóxico & Nenhum método & Biológico \\
Uso do fogo & Sim & Não & Sim \\
Prática para evitar a degradação do solo & Não & Sim & Boa \\
Faz uso de esterco & Não & Sim & \\
Área de reserva nativa na comunidade & Não & Regular & \\
Preservação da reserva nativa & Ruim & & \\
\hline
\end{tabular}

Para a composição do Índice de Sustentabilidade (IS) foram utilizados os indicadores com base nos índices de Qualidade de Vida, Capital Social e Ambiental. Desta forma, o Índice de Sustentabilidade das comunidades foi definido conforme a Equação 3.

$\mathrm{IS}=\frac{1}{\mathrm{k}} \sum_{\mathrm{h}=1}^{\mathrm{k}} \mathrm{I}_{\mathrm{h}}$

Em que: IS: Índice de Sustentabilidade; I: Escore do h-ésimo índice; h: 1,..,k (índices).

A caracterização de todos os índices foi definida conforme Khan \& Silva (2002), quanto mais próximo de 1 maior será o nível de representação do índice. Assim, considerou-se valores de baixo nível os índices entre 0 e 0,49 , médio nível entre 0,50 e 0,79 e índice de elevado nível com valor entre 0,80 e 1,00 .

\section{RESULTADOS E DISCUSSÃO}

A faixa etária dos produtores rurais no município de Caicó apresentou diferença na comparação entre os residentes na zona urbana e rural, com intervalos assimétricos ao valor mediano, sendo a maior amplitude verificada pelos produtores que moram na zona rural, com intervalo de 37 a 74 anos e mediana de 57 anos, sendo $60 \%$ do gênero masculino. Os produtores residentes na zona urbana também apresentaram maior parcela do gênero masculino, cerca de $65 \%$, com faixa etária entre 47 e 71 anos com mediana de 60 anos. O maior e menor valor da idade dos produtores observado foram, respectivamente, 84 e 23 anos registrada entre os residentes na zona rural (Figura 2).

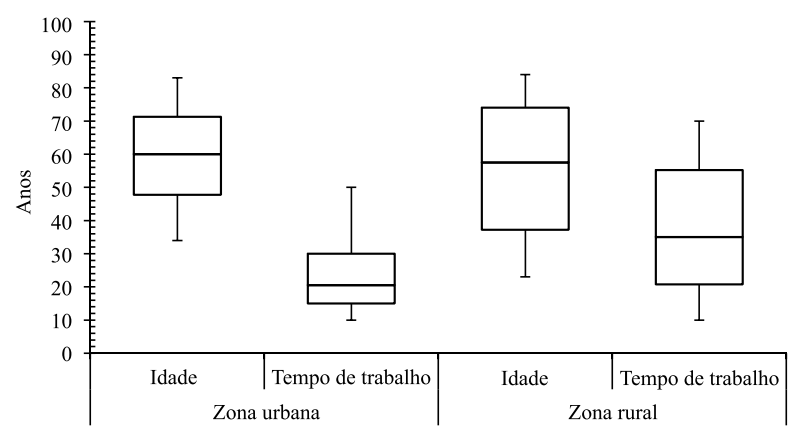

Figura 2 - Faixa etária e tempo de trabalho em atividades agropecuárias dos produtores rurais do município de Caicó no Estado do Rio Grande do Norte.

Na Figura 2, também verifica-se o tempo de atuação dos produtores em atividades rurais, que para os residentes na zona rural, a faixa de tempo mais ampla (20 a 55 anos) registrando mediana de 35 anos e valor máximo e mínimo de 70 e 10 anos. Para os produtores que residem na zona urbana, a faixa de concentração apresentou-se entre 15 a 30 anos de trabalho com mediana de 20 anos.

O tempo de trabalho em atividades rurais dos produtores no município de Caicó está relacionado com a tradição agropecuária das famílias e a cultura da própria região. Sousa (2013) observou em assentamentos no 
município de Pombal sertão paraibano que 93\% dos trabalhadores iniciaram como crianças ou adolescentes em atividades agropecuárias.

Na Figura 3, observa-se que o grau de escolaridade dos produtores rurais do municipio de Caicó demonstrou-se diferente entre os que residem na zona urbana e rural, em que os moradores da cidade apresentaram maiores níveis de escolaridade, sendo a formação em cursos superiores e ensino médio completo, respectivamente, 40 e $30 \%$ dessa amostra. Para os produtores residentes na zona rural, o ensino fundamental completo e os que apenas assinam seu nome predominaram a caracterização, registrando percentual de 35 e $30 \%$ respectivamente.

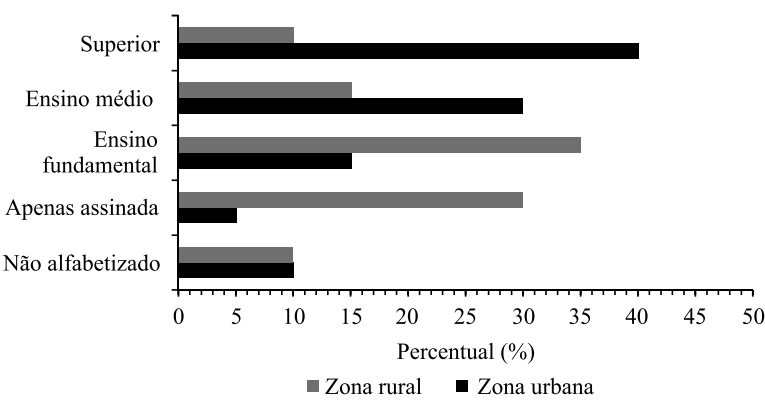

Figura 3 - Perfil dos produtores rurais em relação ao grau de escolaridade no município de Caicó no Rio Grande do Norte, Brasil.

Observa-se também que o percentual de produtores analfabetos registrados foi de $10 \%$ para as duas situações, demonstrando assim um alto índice dentro dos trabalhadores, tendo em vista, as políticas destinadas ao fim do analfabetismo entre jovens e adultos no país ainda necessitar de ações com esse publico (Figura 3).

A discrepância observada ao analisar o nível de escolaridade dá-se pelo fato de que os produtores residentes na zona urbana têm mais acesso a escolas de boa qualidade, facilidade de locomoção e oportunidades de qualificação, enquanto os produtores residentes da zona rural enfrentam dificuldades em frequentar escolas, geralmente começam a trabalhar muito cedo para contribuir com a renda da família, existindo também a questão da dificuldade em se locomover, visto que as escolas da zona rural concentram alunos de várias comunidades.

Em trabalho realizado na região do seridó do estado do Rio Grande do Norte, verificou-se baixo nível de escolaridade dos habitantes de assentamentos rurais, com 39\% de analfabetos (Lima et al., 2017), ressaltando os dados apresentados nessa pesquisa com a grande quantidade de produtores com baixo grau de escolaridade estão principalmente na zona rural.

De acordo com Ney \& Hoffmann (2009) a baixa escolaridade dos produtores rurais dificulta $\mathrm{o}$ desenvolvimento do setor agrícola, pois, com a escassez de capital humano qualificado, inviabilizam a ascensão aos níveis de produtividade e renda necessários à expansão da produção agrícola.

Entre as atividades agropecuárias realizadas pelos produtores rurais do município de Caicó, a bovinocultura e ovinocultura são melhores avaliadas em relação ao fator econômico, em que foram atribuídos valores de forma crescente em relação à preferência da atividade, ou seja, as que receberam melhor avaliação obtiveram maiores valores. Ainda para a atividade agropecuária, observa-se o destaque da avicultura e suinocultura para os produtores que residem na zona rural. Em relação as atividades agrícolas, apenas a horticultura foi mencionada pelos produtores, tendo uma melhor avaliação pelos que residem na zona urbana (Figura 4).

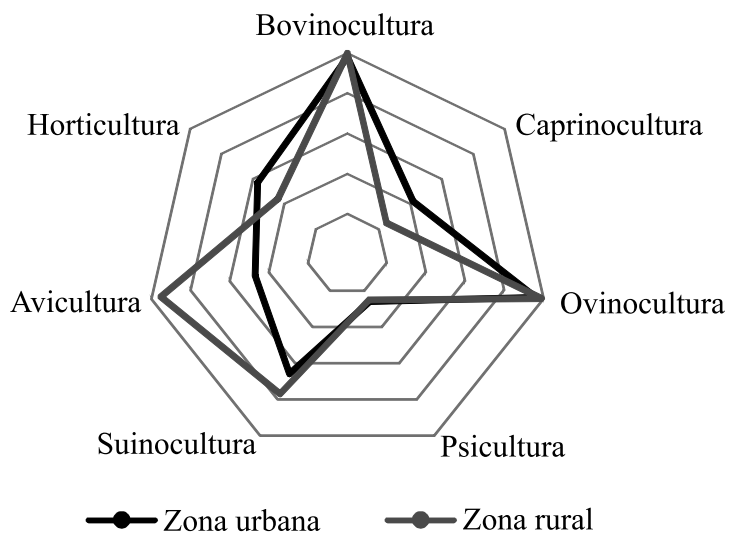

Figura 4 - Atividades desenvolvidas pelos produtores rurais em relação ao fator econômico no município de Caicó no Estado do Rio Grande do Norte, Brasil. Marcadores mais próximos dos eixos significa melhor desempenho econômico.

As atividades agropecuárias de bovinocultura e ovinocultura tiveram maior destaque, pois essas são as mais praticadas pelos produtores tendo em vista que ambos podem ser destinados para a produção de leite e carne. A região em que o município de Caicó encontra-se situado é destaque na pecuária, na quantidade de rebanhos, principalmente para produção de leite, sendo a região caracterizada como bacia leiteira do estado do Rio Grande do Norte (Azevedo, 2013). 
$\mathrm{Na}$ avaliação do Índice de Qualidade de Vida (IQV) dos produtores rurais do município de Caicó (Tabela 4) observou-se diferença na comparação entre os moradores na zona urbana e rural, em que os da sede do município obtiveram IQV caracterizado como elevado, com valor de 0,992. Esse resultado é decorrente da disponibilidade de serviços públicos, e assim apresentando os melhores desempenhos em todos os indicadores. Na zona rural o IQV demostrou resultado médio de acordo com os parâmetros de caracterização, com valor de 0,653 . Esses resultados estão relacionados principalmente a falta de pontos de lazer, como praça pública, ginásios, entre outros, próximos às residências dos produtores e até mesmo a ausência nas próprias comunidades rurais.

Tabela 4 - Índice de Qualidade de Vida (IQV) dos produtores rurais do município de Caicó. Rio Grande do Norte, Brasil. Dados em valores absolutos e contribuição em percentagem (\%)

\begin{tabular}{lcccc}
\hline \multirow{2}{*}{ Indicadores } & \multicolumn{2}{c}{ Zona urbana } & \multicolumn{2}{c}{ Zona rural } \\
\cline { 2 - 5 } & IQV & $\%$ & IQV & $\%$ \\
\hline Educação & 0,158 & $16 \%$ & 0,105 & $16 \%$ \\
Saúde & 0,158 & $16 \%$ & 0,105 & $16 \%$ \\
Habitação & 0,158 & $16 \%$ & 0,158 & $24 \%$ \\
Aspectos sanitários & 0,211 & $21 \%$ & 0,105 & $16 \%$ \\
Lazer & 0,158 & $16 \%$ & 0,053 & $8 \%$ \\
Bens duráveis & 0,150 & $15 \%$ & 0,126 & $19 \%$ \\
Índice de Qualidade de & \multicolumn{2}{c}{0,992} & \multicolumn{2}{c}{0,653} \\
Vida (IQV) & \multicolumn{2}{c}{} \\
\hline
\end{tabular}

Tabela 5 - Índice de Capital Social (ICS) dos produtores rurais do município de Caicó, Rio Grande do Norte, Brasil. Dados em valores absolutos e contribuição em percentagem (\%)

\begin{tabular}{|c|c|c|c|c|}
\hline \multirow{2}{*}{ Indicadores } & \multicolumn{2}{|c|}{ Zona urbana } & \multicolumn{2}{|c|}{ Zona rural } \\
\hline & ICS & $\%$ & ICS & $\%$ \\
\hline Participação ativa nas atividades com a associação a qual é filiado & 0,0 & $0 \%$ & 0,075 & $12 \%$ \\
\hline Apresentação de sugestões em reunião & 0,0 & $0 \%$ & 0,02 & $3 \%$ \\
\hline Apreciação e aprovação nas reuniões das sugestões apresentadas & 0,0 & $0 \%$ & 0,095 & $15 \%$ \\
\hline Apreciação e aprovação em reuniões das decisões da associação & 0,0 & $0 \%$ & 0,085 & $13 \%$ \\
\hline Execução das decisões tomadas nas reuniões, pela diretoria & 0,0 & $0 \%$ & 0,075 & $12 \%$ \\
\hline Submissão e aprovação dos investimentos da associação & 0,0 & $0 \%$ & 0,095 & $15 \%$ \\
\hline Filiação a sindicato rural & 0,03 & $40 \%$ & 0,09 & $14 \%$ \\
\hline Venda de produtos para cooperativa & 0,01 & $13 \%$ & 0,035 & $5 \%$ \\
\hline Participação na Política Municipal & 0,015 & $20 \%$ & 0,0 & $0 \%$ \\
\hline Participação em atividades Culturais & 0,02 & $27 \%$ & 0,08 & $12 \%$ \\
\hline Índice de Capital Social (ICS) & \multicolumn{2}{|c|}{0,075} & \multicolumn{2}{|c|}{0,65} \\
\hline
\end{tabular}

No estado do Rio Grande Norte, Sousa et al. (2005) estudou a sustentabilidade de produtores de assentamentos rurais no município de Mossoró, e verificou IQV geral no valor de 0,479 , sendo considerado abaixo do valor médio, em que o indicador que teve menor contribuição foi lazer, com apenas $6 \%$, e a maior contribuição foi habitação com $25 \%$. Essas contribuições assemelham-se com as observadas para a zona rural nesse estudo.

Na Tabela 5, verifica-se que o Índice de Capital Social (ICS) apresentou valor de 0,65 para os produtores que residem na zona rural, resultado considerado médio, associando-se a participação ativa dos produtores nas atividades de associações a qual é filiado. Para os produtores que moram na sede do município, o índice obteve valor de 0,075 , indicando assim ICS de baixo nível.

A grande diferença gerada ao analisar o ICS entre os produtores da zona rural e urbana está relacionada com o fato de que aqueles que residem na sede do município não participam de associações rurais e também não são filiados aos sindicatos rurais, fazendo com que haja a inexistência de articulação do associativismo desses produtores.

O Índice Ambiental (IA) que apresenta como indicadores as práticas utilizadas pelos produtores atreladas a preservação do meio ambiente, em que verificou-se conforme a Tabela 6 que a maior participação na composição do IA é dada pelo indicador relacionado a preservação da reserva nativa, com contribuição de 28 e $25 \%$, resultando nos índices de 0,46 e 0,455 para os produtores que residem na zona urbana e rural, respectivamente. A utilização de fogo na atividade agropecuária foi o indicador que apresentou menor contribuição ao IA das duas caracterizações da amostra, ressaltando a semelhança dos resultados nesse índice, que foi definido como de baixo nível de preservação ambiental. 
Tabela 6 - Índice Ambiental (IA) dos produtores rurais do município de Caicó, Rio Grande do Norte, Brasil. Dados em valores absolutos e contribuição em percentagem (\%)

\begin{tabular}{lcccc}
\hline \multirow{2}{*}{ Indicadores } & \multicolumn{2}{c}{ Zona urbana } & \multicolumn{2}{c}{ Zona rural } \\
\cline { 2 - 5 } & IA & $\%$ & IA & $\%$ \\
\hline É feita conservação do solo & 0,105 & $23 \%$ & 0,1 & $22 \%$ \\
Utiliza método de controle fitossanitário na unidade produtiva & 0,04 & $9 \%$ & 0,055 & $12 \%$ \\
Faz uso do fogo em atividades agropecuárias & 0,02 & $4 \%$ & 0,005 & $1 \%$ \\
Existe prática de plantio para evitar a degradação do solo & 0,035 & $8 \%$ & 0,06 & $13 \%$ \\
Faz uso de esterco & 0,075 & $16 \%$ & 0,085 & $19 \%$ \\
Existe área de reserva nativa na comunidade & 0,055 & $12 \%$ & 0,035 & $8 \%$ \\
Preservação da reserva nativa & 0,13 & $28 \%$ & 0,115 & $25 \%$ \\
\hline Índice Ambiental (IA) & \multicolumn{2}{c}{0,46} & & 0,455 \\
\hline
\end{tabular}

Nota-se na Figura 4, uma das atividades de maior geração de renda é a bovinocultura sendo também a mais praticada, o uso de queimadas para limpeza da terra e instalação de pastagem, podem justificar o fato desse indicador ter sido o que menos contribuiu para a formação do baixo IA.

Usando indicadores semelhantes aos desse trabalho, Sousa et al. (2017) também constatou avaliando as práticas de manejo e preservação do meio ambiente desempenho de baixo nível dos agricultores familiares no município de Barro no Estado do Ceará.

Na Tabela 7 verifica-se a composição do Índice de Sustentabilidade (IS) obtido a partir dos indicadores compostos pela qualidade de vida, capital social e ambiental, para os produtores rurais de Caicó. Os indicadores de maior contribuição nas duas amostras foi qualidade de vida com 65 e $37 \%$, sendo que os IS apresentaram valores de 0,509 e 0,586 para os produtores que residem na zona urbana e rural respectivamente.
Verifica-se também que a preservação ambiental dos produtores (Tabela 6) e a participação em grupos sociais pelos moradores da zona urbana (Tabela 5) caracterizadas como baixo nível, também demostraram baixa contribuição na composição do IS.

A atuação negativa desses indicadores e a classificação de médio nível de sustentabilidade também é observada em outros municípios nordestinos. Na Paraíba os produtores rurais de municípios do sertão e do cariri também foram classificados como sustentabilidade de nível médio, tendo o indicador de preservação ambiental na maioria dos casos a menor contribuição para formação do índice (Pinto Junior et al., 2018; Santos et al., 2018).

Amorim et al. (2014) avaliando a sustentabilidade do município de Caicó com o uso do Barômetro da Sustentabilidade a partir das dimensões sociais econômicas e institucionais, definiu o índice de bem-estar humano como sendo de nível intermediário de sustentabilidade e na classificação geral, pelo método, o município enquadrou-se

Tabela 7 - Índice Sustentabilidade (IS) de dos produtores rurais do município de Caicó, Rio Grande do Norte, Brasil. Dados em valores absolutos e contribuição em percentagem (\%)

\begin{tabular}{lcccc}
\hline \multirow{2}{*}{ Indicadores } & \multicolumn{2}{c}{ Zona urbana } & \multicolumn{2}{c}{ Zona rural } \\
\cline { 2 - 5 } & IS & $\%$ & IS & $\%$ \\
\hline Qualidade de vida & 0,331 & $65 \%$ & 0,217 & $37 \%$ \\
Capital Social & 0,025 & $5 \%$ & 0,217 & $37 \%$ \\
Ambiental & 0,153 & $30 \%$ & 0,152 & $26 \%$ \\
\hline Índice de Sustentabilidade (IS) & \multicolumn{2}{c}{0,509} & \multicolumn{2}{c}{0,586} \\
\hline
\end{tabular}


na condição de potencialmente insustentável, alertando para a necessidade de adoção de práticas políticas e sociais que favoreçam melhores condições sustentáveis.

\section{CONCLUSÕES}

Os produtores rurais de Caicó no Rio Grande do Norte executam atividades agrícolas e agropecuárias com sustentabilidade média, com indicadores que retratam as diferenças entre os produtores que residem na zona urbana e rural.

Os produtores que residem na zona urbana têm alta qualidade de vida e baixa participação em entidades sociais. Os produtores que residem na zona rural têm problemas com falta de estruturas de lazer e aspectos sanitários, assim diminuindo as condições de qualidade de vida desses moradores.

Os indicadores ambientais apontam semelhança entre as ações dos produtores, demostrando à necessidade de rever algumas práticas realizadas, que não favorecem o meio ambiente e com isso prejudica a sustentabilidade da produção rural local.

\section{LITERATURA CITADA}

AMORIM, A.S.; ARAÚJO, M.F.F.; CÂNDIDO, G.A. Uso do barômetro da sustentabilidade para avaliação de um município localizado em região semiárida do nordeste brasileiro. Desenvolvimento em questão, v.12, n.25, p.189-217, 2014. http://dx.doi.org/10.21527/22376453.2014.25.189-217

AZEVEDO, F.F. Reestruturação produtiva no Rio Grande do Norte. Mercator, v.12, n.2, p.113-132, 2013.

Barros, R.T.V.; Silveira, Á.V.F. Uso de indicadores de sustentabilidade para avaliação da gestão de resíduos sólidos urbanos na Região Metropolitana de Belo Horizonte. Engenharia Sanitária e Ambiental, v.24, n.2, p.411-423 2019 .

ELKINGTON, J. Cannibals with Forks: The triple bottom line of 21st century business. Capstone: Oxford. 1997. 272 p.

FERNANDES, A.V.; SILVA, L.M.R.; KHAN, A.S. Reserva extrativista do rio Cajari: sustentabilidade e qualidade de vida. Revista de Economia e Sociologia Rural, v.35, n.3, p.119-140, 1997.

IBGE. Instituto Brasileiro de Geografia e Estatística. Sinopse do censo demográfico 2010. Rio de Janeiro, 2011. 261p. Disponível em: <http://www.ibge.gov.br/home/ estatistica/populacao/censo2010/sinopse.pdf.> Acesso em: 10 out. 2017.

KHAN, A.S.; SILVA, A.T.B. Reforma agrária solidária, assistência técnica e desenvolvimento rural no estado do Ceará. Revista Econômica do Nordeste, v.33, n.3, p.593614, 2002.

LIMA, A.F.; ARAÚJO, B.V.S.; OLIVEIRA, C.S.P. Caracterização da agricultura familiar em assentamentos da Região oeste do Rio Grande do Norte. Revista Cientifica Rural, v.19, n.1, p.11-19, 2017.

LOUREIRO, S.M.; PEREIRA, V.L.D.V.; PACHECO JUNIOR, W. A sustentabilidade e o desenvolvimento sustentável na educação em engenharia. Revista Eletrônica em Gestão, Educação e Tecnologia Ambiental, v.20, n.1, p.306-324, 2016. http://dx.doi. org/10.5902/2236117019818.

NEY, M.G.; HOFFMANN, R. Educação, concentração fundiária e desigualdade de rendimentos no meio rural brasileiro. Revista de Economia e Sociologia Rural, v.47, n.1, p.147-182, 2009. http://dx.doi.org/10.1590/S010320032009000100006

PINTO JUNIOR, V.M.; GONDIM, A.R.O.; MARACAJÁ, P.B.; ANDRADE, A.B.A. Sustentabilidade agropecuária de produtores rurais em municípios do Sertão da Paraíba. Revista de Gestão Social e Ambiental, v.12, n.3, p.77-94, 2018. http://dx.doi.org/10.24857/rgsa.v12i3.1601

SALES, R.M.M.; CÂNDIDO, G.A. Aplicação do sistema de indicadores do desenvolvimento alternativo e sustentável na agricultura familiar de Várzea Comprida dos Oliveiras - Pombal/PB. Revista Verde de Agroecologia e Desenvolvimento Sustentável, v.9, n.2, p.144-161, 2014.

SANTOS, J.L.G.; ANDRADE, A.B.A.; MARACAJÁ, P.B. Comportamento sustentável dos produtores rurais no Cariri e no Sertão da Paraíba. Revista Brasileira de Gestão e Desenvolvimento Regional, v.14, n.5, p.62-73, 2018.

SEIDLER, E.P.; ANDREATTA, T.; CIECHOWICZ, I.F.S.; SPANEVELLO, R.M. A temática da sustentabilidade no meio rural a partir de uma abordagem científica. Revista Verde, v.13, n.5, p.572-580, 2018. https://doi.org/10.18378/ rvads.v13i5.5901

SOUSA, L.C.F.S. Sustentabilidade da apicultura: Aspectos socioeconômicos e ambientais em assentamentos rurais no semiárido paraibano. 2013. 78f. Dissertação (Mestrado em Sistemas Agroindustriais) - Curso de Pós Graduação em Sistemas Agroindustriais, Universidade Federal de Campina Grande, Pombal. 
SOUSA, M.C.; KHAN, A.S.; PASSOS, A.T.B.; LIMA, P.V.P.S. Sustentabilidade da agricultura familiar em assentamentos de reforma agrária no Rio Grande do Norte. Revista Econômica do Nordeste, v.36, n.1, p.96-120, 2005.
SOUSA, W.D.; MELO, F.K.E.; SOUSA, E.P. Sustentabilidade da agricultura familiar no município de Barro - CE. Revista Gestão \& Sustentabilidade Ambiental, v.6, n.2, p.302-327, 2017. http://dx.doi.org/10.19177/rgsa. v6e22017302-327.

Recebido para publicação em 19/02/2019 e aprovado em 17/12/2019. 